\title{
Influence of external environmental factors on the productivity of mulberry silkworm (Bombyx mori $L$ ) in different sizes of silk breeding organizations
}

\author{
$K$ Jumagulov ${ }^{1, *}, N$ Rajabov $^{1}, K H$ Rakhmanova $^{1}, O$. Karimov $^{1}, Z$ Sharapova ${ }^{1}$, and $S H$ \\ Khalikova $^{1}$ \\ ${ }^{1}$ Tashkent State Agrarian University, University str., 2, Tashkent province, 100140 Uzbekistan
}

\begin{abstract}
The information presented in this article suggests that the larger the silkworm breeding organization (SBO), the harder it is to maintain a comfortable temperature, relative humidity, and other environmental factors, resulting in the development of silkworm cocoons. differently, the process of implementing agro-technical measures is disrupted. As a result, industrial cocoons are reported to have a yield of $14-17 \%$, viability $22-$ $25 \%$, worm life $7-9$ days and silkworm cocoons $7-13 \%$.
\end{abstract}

\section{Introduction}

Uzbekistan is a world leader in cocoon production, and large-scale reforms are underway to deepen the processing of cocoon raw materials from silkworms into finished products and export them to world markets $[1,2]$.

Silkworms are harvested in the country several times a year. However, the process of feeding silkworms is carried out in residential buildings and unused buildings without the organization of special breeding $[2,4]$. In such silkworm breeding organizations (SBOs) with different sizes, it is difficult to properly adjust the agro-technological requirements in the process of feeding silkworms. As a result, it is more difficult to meet the agro-technical requirements in the process of feeding silkworms, and as a result, the cocoon yield from one box of silkworms decreases sharply $[3,6]$. In turn, this process has a negative impact on the quality and technological performance of cocoons. Of course, in order to achieve high and quality yields from mulberry silkworms, it is necessary to create a favorable ecological environment for them in SBOs. The normal development of the mulberry silkworm depends directly on the external environment [2-6].

The external environment is defined as factors such as the light and temperature of the sun falling on the earth, the humidity of the air in nature, the feeding area, the composition of the air, the amount of nutrients. The external environment affects all living organisms. Mulberry silkworm receives energy from the external environment: leaves, oxygen and

\footnotetext{
${ }^{*}$ Corresponding author: k.k.jumagulov@yandex.com
} 
light. At the same time, the worm releases its living products: garbage, water, carbon dioxide and heat into the environment [7,9].

The normal course of physiological processes in the body of mulberry silkworm depends on the state of the external environment. Without studying the external environment, it is impossible to develop rational methods of feeding silkworms in the future $[1,4,7]$.

As a result of scientific research conducted by scientists in recent years, great practical results have been achieved in further accelerating the feeding rate of mulberry silkworms. As a result, the feeding period was reduced from 30-32 days to 21-23 days [5-8]. Every organism changes under the influence of the external environment, at the same time this organism also changes the environment around it. As a result of a clear understanding of these interactions, research in the biological sciences has revealed ways to change the nature of organisms, and has developed new methods in a conscious and planned manner $[9,10]$.

It should be noted that the better we understand the relationship between the organism and the external environment, the better we can manage the organism, taking advantage of the opportunity to regulate and create the external environment. Therefore, the interaction between the organism and the environment is of particular importance for agriculture, and good breeds of animals are formed only as a result of the application of good agronomics and good zootechnics $[11,12]$.

Living beings, in accordance with their nature, select different conditions from the surrounding environment, assimilate them, and form their own bodies according to their own laws of individual development, that is, heredity. By external conditions we mean processes that are assimilated, and by internal conditions we mean processes that are assimilated [1, 7-11].

The life of an organism is very complex and undergoes countless legal processes and changes. As a result, the food that enters the body from the external environment is assimilated by the living body after various changes, from external to internal conditions. It is these internal conditions that become living matter and nourish other cells and particles in the body, and become external to them. All the environmental conditions in a unit, regardless of how important each of them is for that organism, are called environmental conditions [7-14].

\section{Materials and methods}

It is known that in order to obtain a rich and quality cocoon crop from silkworms, it is necessary to have SBOs with all the conditions. According to the recommendations of scientists and advanced cocoons, an SBO with a volume of $80-85 \mathrm{~m}^{3}$ will be needed to feed a box of silkworms and obtain quality cocoons from it [1].

A group of scientists from the Laboratory of Silk Mechanization of the Silk Research Institute recommended the development and implementation of design projects for 3-5 boxes of fully equipped special SBOs.

In accordance with the decision made in Uzbekistan in 2012, 50-75 boxes of silkworm rearing and cocoon breeding facilities were built at the cotton mills of the Uzpakhtasanoat Association and their 196 cotton-receiving facilities, which were put into operation in 2013 (Fig. 1). 

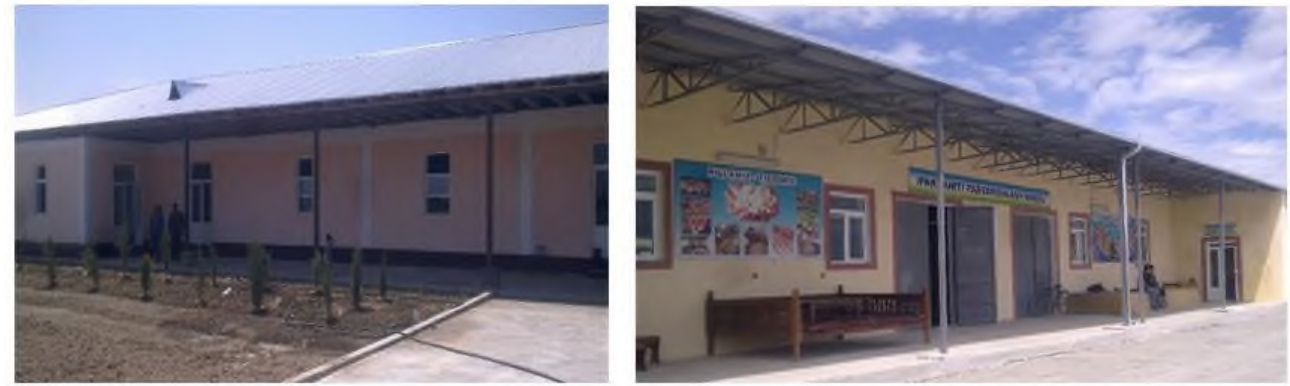

Fig. 1. Appearance of special large-capacity SBOs for 50-75 boxes established in the country.

The height of such SBOs is 5 meters, the prefabricated sockets are installed in 5 storeys. The building also has an incubator, a leaf storage room and a room for feeding worms, as well as rest and other necessary rooms.

However, in these special SBOs, the worm feeding rooms are designed for general feeding without being divided into sections (Fig. 2).
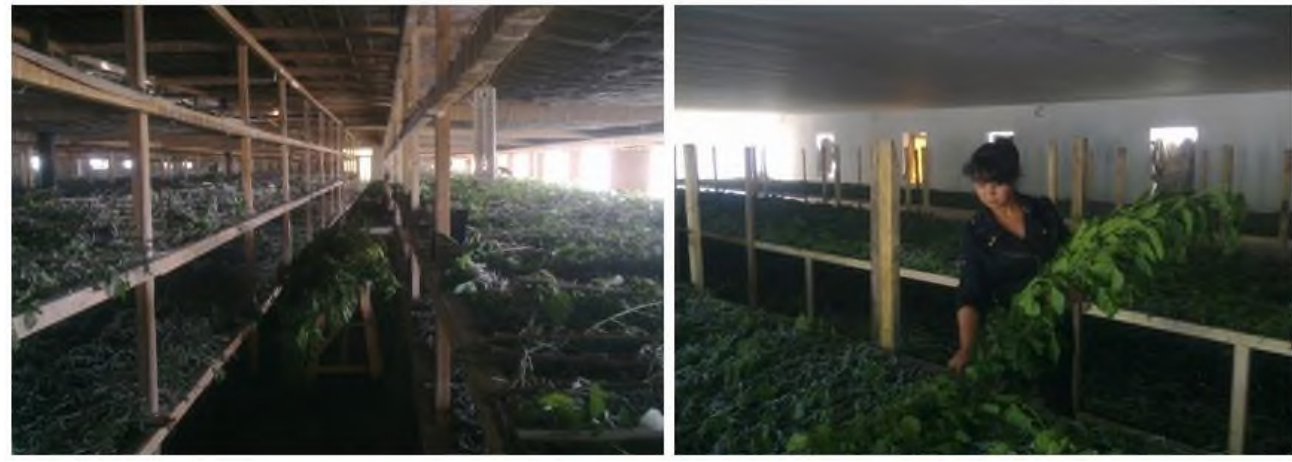

Fig. 2. Interior view of special large SBOs for 50-75 boxes.

It has been commissioned without taking into account all the features (SBO temperature, humidity, air exchange and light fall) necessary to feed the silkworm and get a quality crop from it. The inability to control temperature and humidity levels, especially in such large-scale SBOs, leads to silkworm disease and death. In addition, as a result of such a large number (50-75 boxes) of silkworm care in one place, the rapid spread of the disease is observed. As a result, cocoon yields fall sharply and their quality does not meet demand.

In order to compare our observations with special SBOs built in Boka, Akkurgan and Piskent districts of Tashkent region, silkworms were kept in 5 boxes of "Gulomjon Amirbek Fayz" farm and 4.5 boxes of "Erkinmirzo Azimjon" farm in Boka district. was carried out. In these SBOs, local and imported silkworms were examined and significant results were obtained. Biological parameters of silkworms fed in SBOs (viability, agerelated transition, infestation) were determined. Productivity and quality indicators of the obtained cocoons were determined.

\section{Results and discussion}

In our study, it was found that the larger the SBO volume, the more difficult it is to control the temperature regime in them. In particular, due to the large volume of SBO $\left(4,250 \mathrm{~m}^{3}-\right.$ 
$6,375 \mathrm{~m}^{3}$ ) in which $50-75$ boxes of silkworms are fed, it was shown that the temperature and moisture content in it vary in the upper and lower parts of the SBO (Table 1).

Table 1. Variation of temperature readings in special SBOs of different sizes.

\begin{tabular}{|c|c|c|c|c|c|}
\hline 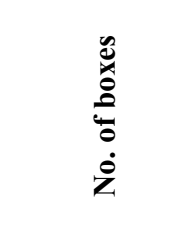 & 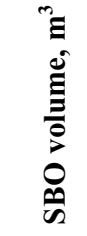 & 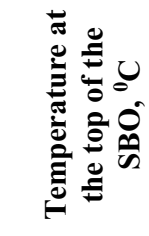 & 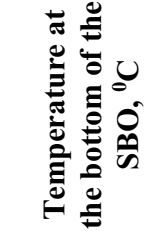 & 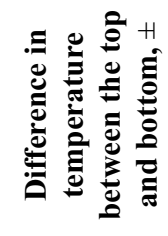 & Pd \\
\hline 50 & 4,250 & $28.4 \pm 0.25$ & $23.1 \pm 0.35$ & $5.3 \pm 0.19$ & 0.986 \\
\hline 75 & 6,375 & $29.5 \pm 0.37$ & $22.2 \pm 0.40$ & $7.3 \pm 0.21$ & 0.989 \\
\hline $\begin{array}{c}5 \\
\text { (comparative) }\end{array}$ & 425 & $25.2 \pm 0.31$ & $24.3 \pm 0.27$ & $0.9 \pm 0.02$ & - \\
\hline
\end{tabular}

From the data presented in Table 1 above, it can be seen that the larger the SBO volume, the different the temperature index in them at the top and bottom of the SBO. In particular, during the worm feeding period, the temperature in the upper part of the SBO for $50-75$ boxes $\left(4,250 \mathrm{~m}^{3}-6,375 \mathrm{~m}^{3}\right)$ was $28.4-29.5^{\circ} \mathrm{C}$, while in the lower part it was $22.2-$ $23.1^{\circ} \mathrm{C}$. The temperature difference between the upper and lower part of the SBO was 5.3$7.3^{\circ} \mathrm{C}$.

The temperature difference between the upper and lower part of the SBO for 5 boxes $\left(425 \mathrm{~m}^{3}\right)$ in the control variant was only $0.9^{\circ} \mathrm{C}$.

It should be noted that when the temperature in the SBO falls below normal, the vital processes of the silkworm slow down. When the low temperature rises to a certain level, the development of worms is much faster. Conversely, when body temperature exceeds a moderate level, these processes begin to slow down due to disruption of biological processes. In some cases, such disorders may be due to the breakdown of enzymes. As the temperature rises, the potency of the enzymes increases. As the temperature decreases, the activity of the enzymes begins to decrease, as such a temperature breaks down the enzymes, which in turn causes the processes to slow down.

Enzymes of colds are affected when the body temperature is much lower $\left(15-30^{\circ} \mathrm{C}\right)$. Enzymes of colds weaken faster than those of colds. When the temperature is $40^{\circ} \mathrm{C}$, some enzymes in the silkworm's body begin to break down. For example, lipase (an enzyme) that dissolves fat in intestinal juice is broken down within an hour under the influence of temperature. When the temperature is $40^{\circ} \mathrm{C}$, a quarter of this enzyme is broken down, when it is $45^{\circ} \mathrm{C}$ - half, and when it is $70 \mathrm{C}$ - almost all of it is broken down $[13,14]$.

Due to this, the care of silkworms in large-scale special SBOs leads to the fact that their temperature is not maintained at a constant level. As a result, physiological processes in the body of mulberry silkworms are disrupted, and their productivity decreases.

In our scientific studies, it was found that temperature and relative humidity in largescale special SBOs also affect the duration and viability of the worm feeding period (Table 2 and Fig. 3). 
Table 2. Effect of temperature on SBOs built in different sizes on the viability of silkworms.

\begin{tabular}{|c|c|c|c|c|c|}
\hline \multirow{3}{*}{ 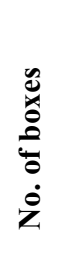 } & \multirow{3}{*}{ 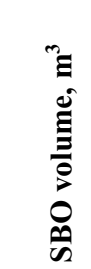 } & \multicolumn{3}{|c|}{ Survival of silkworms, \% } & \multirow{3}{*}{ Pd } \\
\hline & & $\begin{array}{c}\text { At the top } \\
\text { of the } \\
\text { SBO }\end{array}$ & $\begin{array}{l}\text { In the } \\
\text { middle of } \\
\text { the SBO }\end{array}$ & $\begin{array}{c}\text { At the } \\
\text { bottom of the } \\
\text { SBO }\end{array}$ & \\
\hline & & $28-29^{\circ} \mathrm{C}$ & $25-26^{\circ} \mathrm{C}$ & $21-22^{\circ} \mathrm{C}$ & \\
\hline 50 & 4,250 & $41 \pm 0.28$ & $76 \pm 0.41$ & $55 \pm 0.34$ & 0.989 \\
\hline 75 & 6,375 & $51 \pm 0.31$ & $72 \pm 0.38$ & $53 \pm 0.29$ & 0.991 \\
\hline 5 & 425 & $86 \pm 0.37$ & $95 \pm 0.57$ & $88 \pm 0.44$ & - \\
\hline
\end{tabular}

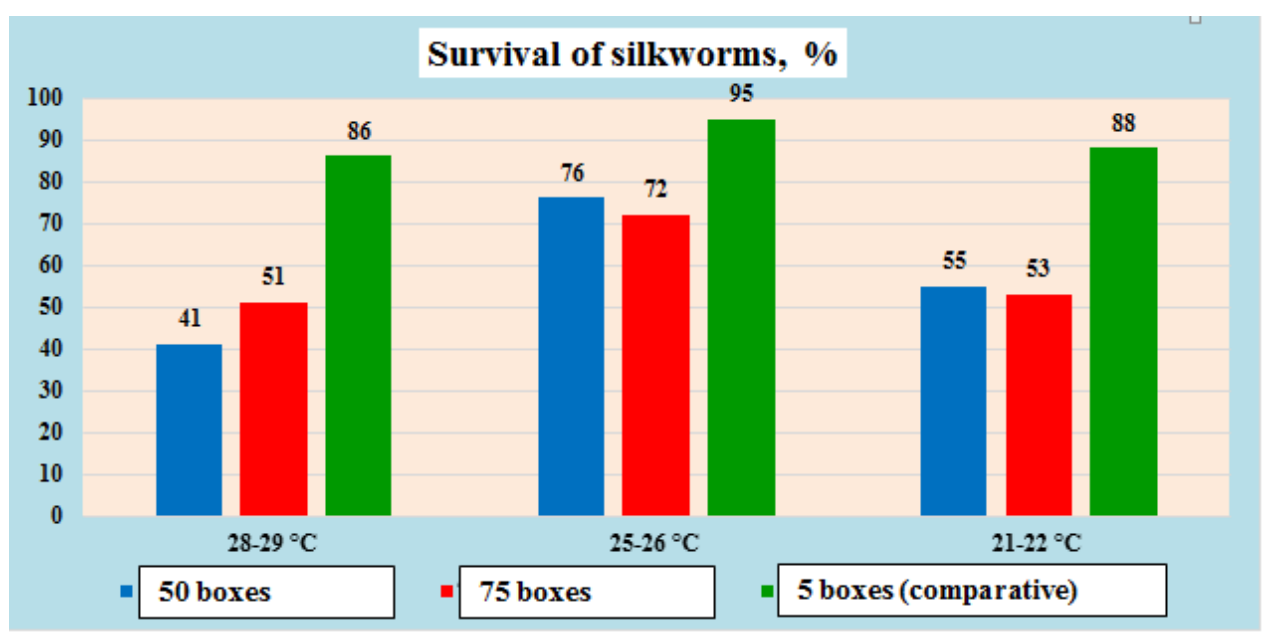

Fig. 3. Effect of temperature on SBOs built in different sizes on the viability of silkworms.

In addition, our research has shown that different levels of temperature (upper and lower) in special SBOs with a large volume have a direct impact on the development of silkworms, their age, and feeding processes. In particular, this process was evident in the development and emergence of silkworms (Fig. 4). 


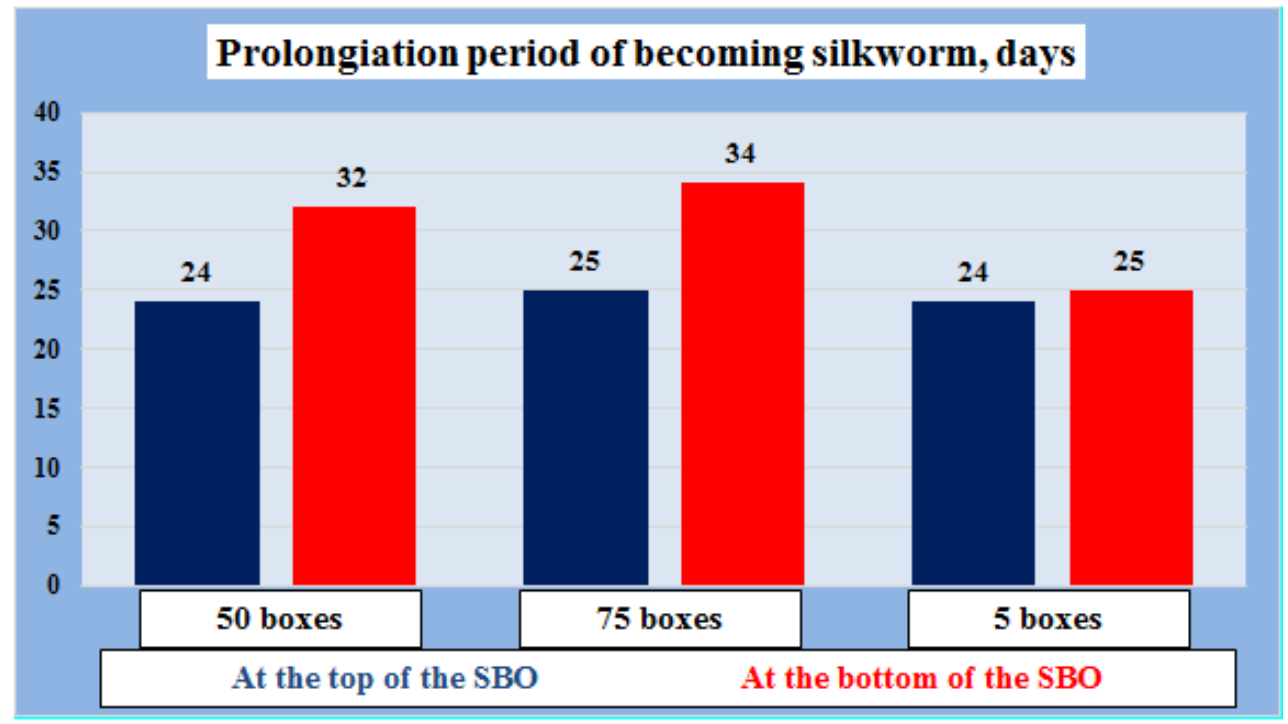

Fig. 4. The effect of temperature between the upper and lower part of a special SBO of different sizes on the development of silk drying.

Temperature variability in the SBO affects not only the development of silkworms but also their performance on the handle (Fig. 5).

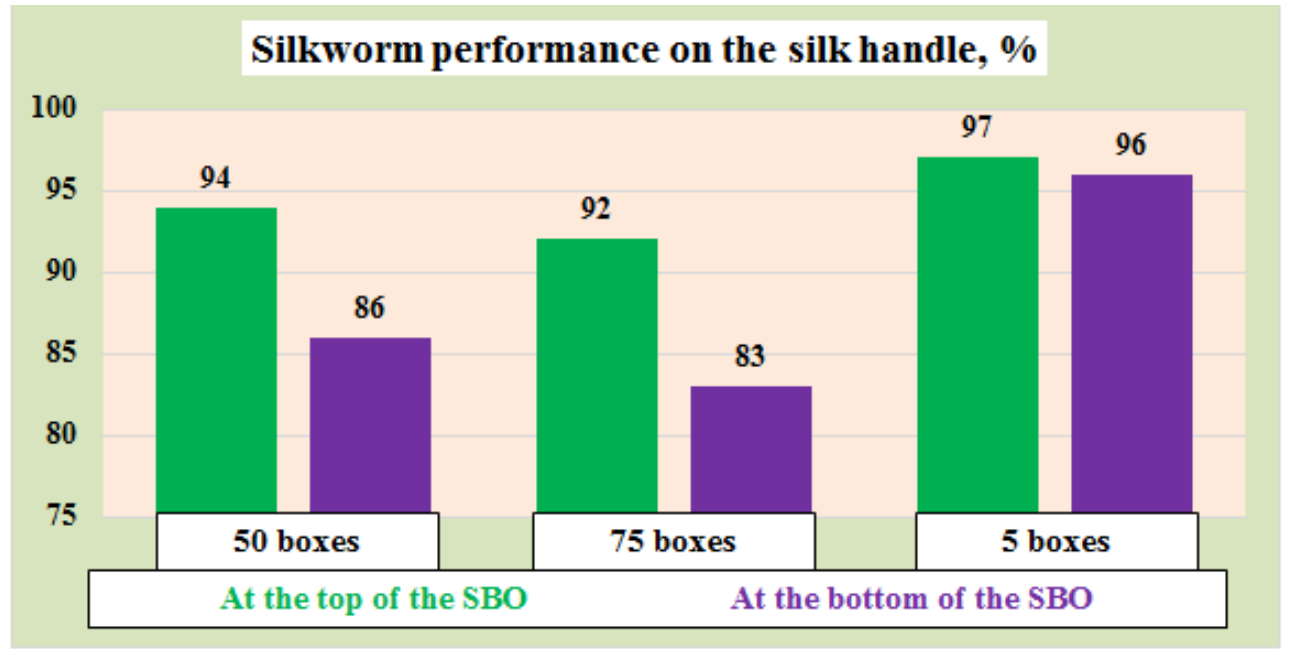

Fig. 5. The effect of temperature on the upper and lower layers of a special SBO of different sizes on the percentage of silk drying.

Based on the above data, it should be noted that the larger the volume of SBOs designed to feed silkworms, the more difficult it is to maintain a constant temperature in them. On the contrary, it has been shown that the smaller the SBO volume, the more likely it is to regulate the temperature readings in it.

It was found that the temperature below or above the norm during the feeding of worms has a negative effect on the activity of the organs in the body of the larva, as mentioned above, in cocoon yield and quality indicators. The results of these experiments are presented in Table 3. 
Table 3. Influence of abnormal temperature changes in worm feeding on cocoon yield and quality.

\begin{tabular}{|c|c|c|c|c|c|c|c|}
\hline \multirow{3}{*}{ 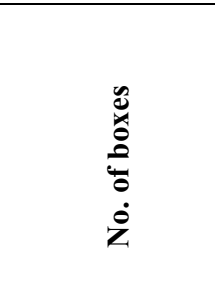 } & \multirow{3}{*}{ 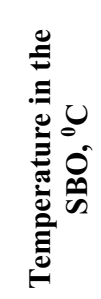 } & \multirow{3}{*}{ 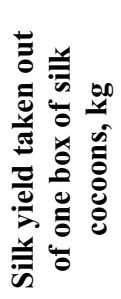 } & \multicolumn{4}{|c|}{ Including } & \multirow{3}{*}{ Pd } \\
\hline & & & \multicolumn{2}{|c|}{$\begin{array}{c}\text { Silk cocoon } \\
\text { with varieties }\end{array}$} & \multicolumn{2}{|c|}{$\begin{array}{c}\text { Silk cocoon } \\
\text { without variety }\end{array}$} & \\
\hline & & & kg & $\%$ & kg & $\%, \mathrm{X} \pm \mathrm{Sx}$ & \\
\hline 50 & $22-23^{0}$ & 67.0 & 55.0 & 82.0 & 12.0 & $18.0 \pm 0.13$ & 0.992 \\
\hline 75 & $28-29^{0}$ & 58.0 & 45.0 & 78.0 & 13.0 & $22.0 \pm 0.17$ & 0.996 \\
\hline 5 (comparative) & $25-26^{0}$ & 77.0 & 71.0 & 92.0 & 6.0 & $11.0 \pm 0.09$ & - \\
\hline
\end{tabular}

In addition, the relative humidity in the SBO also has a direct effect on the normal development of the mulberry silkworm. In special SBOs with large volumes, there are great difficulties in maintaining the relative humidity values required for silkworms at the same time as the temperature in the normative agrotechnical requirements. We devoted our next study to the effect of relative humidity on SBO on silkworm productivity.

Worms were fed in 3 SBOs with different air humidity of special SBOs. At the end of the experiment, the viability of the worms, the length of the worm cycle, and where the larvae wrapped the cocoon were determined. Data on this are given in Table 4.

Table 4. Influence of different air humidity in the SBO on biological parameters of silkworm.

\begin{tabular}{|c|c|c|c|c|c|c|}
\hline \multirow[b]{2}{*}{ No. of boxes } & \multicolumn{2}{|c|}{ Air in the SBO } & \multirow{2}{*}{ 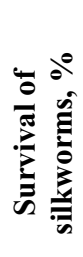 } & \multirow{2}{*}{ 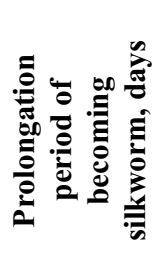 } & \multicolumn{2}{|c|}{$\begin{array}{l}\text { Place of silk } \\
\text { extraction of } \\
\text { cocoons }\end{array}$} \\
\hline & $\begin{array}{c}\text { Temperature, } \\
{ }^{0} \mathrm{C}\end{array}$ & $\begin{array}{c}\text { Humidity, } \\
\%\end{array}$ & & & $\begin{array}{c}\text { Silk } \\
\text { handle, } \\
\%\end{array}$ & $\begin{array}{c}\text { Boxes, } \\
\%\end{array}$ \\
\hline 50 & $25-26^{0} \mathrm{C}$ & 50 & 86.0 & 25 & 87.0 & 13.0 \\
\hline 75 & $25-26^{0} \mathrm{C}$ & 85 & 93.0 & 25 & 85.0 & 15.0 \\
\hline $\begin{array}{c}5 \\
\text { (comparative) }\end{array}$ & $25-26^{0} \mathrm{C}$ & 70 & 96.0 & 24 & 95.0 & 5.0 \\
\hline
\end{tabular}

Data in Table 4 show that when the humidity in the SBO was below the norm $(65-75 \%)$ $(50 \%)$, the survival of the worms decreased by $10.0 \%$ compared to the comparative variant, and the worm period was extended by 1 day. This figure was also reflected in the fact that the humidity in the SBO exceeded the norm, and the survival of the larvae was $85 \%$, a decrease of $3.0 \%$ compared to the comparative variant.

It is known that silkworms begin to cocoon at the end of 5 years when they are full of food. At this time, if the air humidity in the SBO is moderate and the stalk is sufficient, the worms will quickly climb out of the stalks and begin to wrap the cocoon. It is also clear from the data in Table 4 that the disruption of this process is also related to the humidity in the SBO, i.e. when the humidity in the SBO is below the norm, $87.0 \%$ of the worms wrap the cocoons and the remaining $13.0 \%$ in the cocoon. This figure was found to be $95.0 \%$ in the comparative variant and $8 \%$ higher than in the experimental variant. When the air 
humidity in the SBO was above normal, the worms wrapped $85.0 \%$ of the cocoon on the stalk and $15 \%$ on the cocoon. It is self-evident that cocoons wrapped in ghana are of low quality and lead to an increase in the number of cocoons without variety.

\section{Conclusions}

Our observations and research have shown that the larger the size of silkworm reared SBOs, the more difficult it is to maintain a comfortable temperature, relative humidity and other environmental factors, and as a result, the development of silkworms, cocoon wrapping processes vary. , the process of implementing agro-technical measures is disrupted. As a result, industrial cocoons are reported to have a yield of $14-17 \%$, viability $22-25 \%$, worm life 7-9 days and silkworm cocoons $7-13 \%$.

\section{References}

1. N. A. Akhmedov, Voris, 21-52 (2014) (in Uzbek)

2. N. Akhmedov, U. Daniyarov, Davr, 57-72 (2014) (in Russian)

3. CH. Bekkamov, N. Akhmedov, S. Valiev, U. Jumanova, KH. Rakhmanova, Zooveterinary, 9, 36-37 (2010)

4. X. Ruiz, M. Almanza, Chilean journal of agricultural research, 78(4), 569-579 (2018)

5. J. Doreswami, S. Gopal, H. Hagedorn, Journal of insect science, 12(1), 21 (2012)

6. KH. Rakhmanova, N. Akhmedov, Zooveterinary, 5, 37-38 (2011)

7. E. Talebi, G. Subramanya, S. Bakkappa, Journal of Agricultural Biological Science, 5, 52-55 (2010)

8. N. Akhmedov, KH. Rakhmanova, Zooveterinary, 3, 14-17 (2013)

9. SH. Umarov, B. Nasirillaev, N. Rajabov, M. Jumaniyozov, A. Batirova, S. Khudzhamatov, International journal of scientific \& technology research, 9(3), 863866 (2020)

10. S. Navruzov, N. Rajabov,U. Khudayberdieva, International Journal of Research Culture Society, 4(2), 9-11 (2020)

11. N. Rajabov, KH. Fozilova, International Journal for Innovative Research in Multidisciplinary Field, 4(6), 19-23 (2018)

12. V. Rakhmonberdiev, N. Rajabov, KH. Fozilova, International Journal of Research and Development, 5(1), 219-222 (2020)

13. N. Rajabov, SH. Umarov, B. Nasirillaev, KH. Fozilova, Solid State Technology, 63(4), 150-159 (2020)

14. B. Nasirillaev, N. Rajabov, International Scientific Review Of The Problems And Prospects Of Modern Science And Education, 43-46 (2018) 